\title{
Analytical Model for Transient Gasification of Noncharring Thermoplastic Materials
}

\author{
K. D. STECKLER, T. KASHIWAGI and H. R. BAUM \\ Building and Fire Research Laboratory \\ National Institute of Standards and Technology \\ Gaithersburg, Maryland 20899, USA
}

\section{K. KANEMARU}

Department of Mechanical Engineering

Nagasaki University

Nagasaki, Japan

\section{ABSTRACT}

An analytical model is presented for the one-dimensional transient gasification of a noncharring thermoplastic material subjected to a specified, time-dependent external radiant heat flux. The model provides for temperature-dependent thermal properties and time-dependent radiative and convective heat losses from the surface. It assumes that the external radiant flux is absorbed only at the surface and that both the heat of vaporization and vaporization temperature can be specified and are constant. Calculated results are compared to experiments with poly(methyl methacrylate) (PMMA). Agreement between theory and experiment is much better for a high $\left(40 \mathrm{~kW} / \mathrm{m}^{2}\right)$ external radiant flux than for a low (17 $\mathrm{kW} / \mathrm{m}^{2}$ ) external radiant flux. Under the latter condition, sub-surface absorption and degradation processes play a signifjcant role but are not represented in the current model. Variable thermal properties, however, are shown to be non-crucial provided an appropriate effective temperature is chosen for their evaluation.

KEYWORDS: gasification, polymethylmethacrylate, pyrolysis models

\section{INTRODUCTION}

The gasification process under transient heating is of particular interest since it plays a key role in the ignition, flamespread, and burning processes during the early stages of fire growth. In order to incorporate these phenomena into zone-type compartment fire models such as [1], relatively simple but accurate mathematical models of the transient gasification process are needed. In this paper we limit our attention to the condensed phase ( $i . e .$, flux incident upon the surface is specified) and to non-charring thermoplastic materials. 
Gasification models tend to fall into three categories; relatively simple algebraic models, relatively complex partial differential equation (PDE) models, and an intermediate group of analytical models. According to the algebraic models, which are based on the work of Tewarson and Pion [2], the gasification rate is proportional to the net absorbed heat flux once some ignition criterion has been met. Vovelle et al $[3,4]$ showed that during the transient heating of PMMA samples the gasification rate is still proportional to the net absorbed heat flux, but the proportionality factor is a function of the amount of heat absorbed by the solid. Except for thin samples, this functional dependence is independent of the history of the applied heat flux. Volvelle et al [5] have developed a transient numerical PDE mode1 that includes one step Arrenhius type degradation reactions in sub-surface regions that contribute to the gasification rate. PDE mode1s, however, are generally too complex for use in zone-type compartment fire models. Saito et al [6] have developed an analytical model that they have used with some success in correlating experimental transient gasification rates despite that the model assumes negligible heat losses. Delichatsios and deRis [7] developed analytical asymptotic solutions for the surface temperature histories of pyrolyzing materials.

This paper explores a global gasification model that is similar to that mentioned above $[6,7]$ but accounts for temperature-dependent thermal properties and utilizes different approximations. An analytical solution for one-dimensional transient heating and gasification of an opaque thermoplastic is developed and exercised. The solution is expressed in integral form which is amenable to rapid evaluation on a personal computer.

\section{ANALYTICAL SOLUTION}

The overall problem is divided into two pieces as indicated in Fig. 1. The first deals with the preheating period in which a semi-infinite nonreacting opaque solid is heated by an external source of thermal radiation. of this incident radiation, $\dot{q}_{1}^{\prime \prime}$, a fraction $1-r$ is absorbed and the remainder is reflected at the surface of the material. The preheating period ends and the gasification period begins when the surface temperature reaches a specified vaporization temperature, $\mathrm{T}_{\mathrm{v}}$. During the gasification period the surface temperature is fixed at $\mathrm{T}_{\mathrm{v}}$ and the surface regresses owing to the gasification process, which occurs only at the surface. Timedependent radiative and convective heat losses from the surface occur during both periods. The thermal properties of the material can be temperature dependent. The heat of vaporization, $\Delta \mathrm{H}_{v}$, is also constant and the temperatures throughout the solid are continuous at the time of the preheat-to-gasification transition.

\section{Preheating Period}

The preheating problem requires a solution to the one-dimensional heat flow equation

$\frac{\partial}{\partial y}\left(k \frac{\partial T}{\partial y}\right)=\rho_{o} c_{p} \frac{\partial T}{\partial t}, \quad$ for $0<y<\infty, t>0$

subject to the boundary and initial conditions

$\partial T(0, t) / \partial y=-\dot{q}^{\prime \prime}(t) / k, \quad T(\infty, t)=\lim _{y \rightarrow \infty} T(y, t)=T_{0}, \quad T(y, 0)=T_{0}$ 

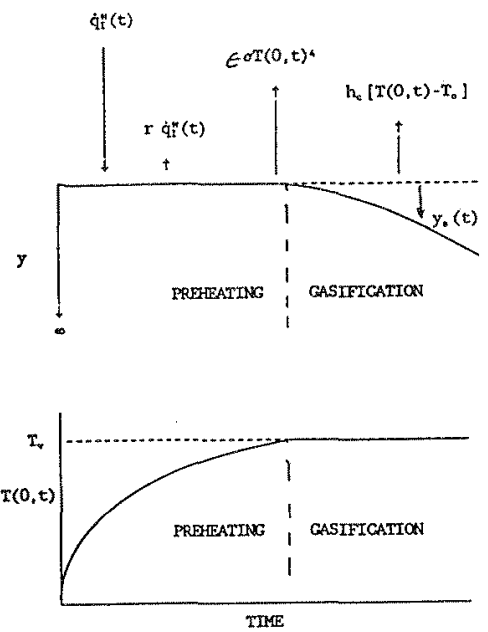

Figure 1. Surface location, $y_{s}(t)$, and surface temperature $T(0, t)$, during preheating and gasification periods.

where $\dot{q}^{\prime \prime}(t)$ is the net heat flux absorbed at the surface; that is,

$\dot{q}^{\prime \prime}(t)=\dot{q}^{\prime \prime}[t ; T(0, t)]=(1-r) \dot{q}_{I}^{\prime \prime}(t)-\epsilon \sigma T(0, t)^{4}-h_{c}[T(0, t)]\left[T(0, t)-T_{0}\right]$

Here the temperature $\mathrm{T}(\mathrm{y}, \mathrm{t})$ of the solid is initially at temperature $\mathrm{T}_{0}$. The solid has a constant density $\rho_{\circ}$, and variable thermal conductivity $k$ (T) and specific heat $c_{p}(T)$, subject to the condition that the thermal diffusivity $\alpha$ is constant. The surface emissivity is denoted by $\varepsilon$, the convective heat transfer coefficient is $h_{c}$, and $\sigma$ is the stefan-Boltzmann constant. Although $\mathrm{k}$ can be any function of $\mathrm{T}$, we will approximate $\mathrm{k}$ as a linear function of $\mathrm{T}$; that is,

$k=k_{0}\left[1+a\left(T-T_{0}\right)\right]$

With these assumptions, Eqs.(1)-(4) can be readily solved using standard techniques [8] to yield the following expression for the surface temperature as a function of time;

$C_{2} T(0, t)^{2}+C_{1} T(0, t)+C_{0}=\frac{\alpha^{3}}{\pi^{3}} \int_{0}^{t} \frac{\dot{q}^{\prime \prime}\left[t_{0}, T\left(0, t_{0}\right)\right] d t_{0}}{\left(t-t_{0}\right)^{\frac{1}{2}}}$

where $\mathrm{C}_{2}=\mathrm{k}_{\mathrm{o}} / 2, \mathrm{C}_{1}=\mathrm{k}_{\mathrm{o}}\left(1-\mathrm{aT} \mathrm{T}_{\mathrm{o}}\right)$, and $\mathrm{C}_{\mathrm{o}}=-\left(1-\mathrm{aT}_{\mathrm{o}} / 2\right) \mathrm{k}_{\mathrm{o}} \mathrm{T}_{\mathrm{o}}$.

\section{Gasification Period}

Since it is assumed that the incident flux is absorbed only at the surface of the material, the mass flux, $\dot{m} "$, from the surface is the product of the density of the material and the surface regression rate, $\mathrm{dy}_{\mathrm{s}} / \mathrm{dt}$; that is, 
$\dot{m} \prime(t)=\rho_{0} \frac{d y_{s}(t)}{d t}$

$\mathrm{dy}_{\mathrm{s}}(\mathrm{t}) / \mathrm{dt}$ is related to the dependent variable $\mathrm{T}$ and the net heat flux

absorbed at the surface through the energy balance at the surface; that is,

$\dot{q} "=\rho_{0} \Delta \mathrm{H}_{v} \frac{d y_{s}}{d t} \cdot k \frac{\partial T(0, t)}{\partial y}$

The problem of finding $\dot{\mathrm{m}} "$ is reduced to finding the temperature gradient at the surface of the condensed phase as a function of time.

Since the surface moves once gasification begins, it is convenient to make the coordinate change

$z=y-y_{s}(t)$

which affixes the coordinate system to the regressing surface. The temperature profile within the condensed phase is then governed by the equations

$\frac{\partial}{\partial z}\left(k \frac{\partial T}{\partial z}\right)=\rho_{0} c_{p}\left(\frac{\partial T}{\partial t}-\frac{d y_{s}}{d t} \frac{\partial T}{\partial z}\right) \quad 0<z<\infty, \quad t>0$

$T(0, t)=T_{v}$,

$T(\infty, t)=T_{0}$

The initial temperature $\mathrm{T}(\mathrm{z}, 0)$ is the temperature profile at the instant gasification begins as obtained from the preheating calculation. The new time origin corresponds to the instant gasification begins. In order to solve Eqs. (9) and (10), it is convenient to introduce the following dimensionless variables:

$\left.\begin{array}{l}\Theta(y, t) \equiv \int_{T_{0}}^{T(y, t)} k d T / I_{v}, \quad \zeta=z^{*} d y_{s}^{*} / d t^{*}, \quad r=\int_{0}^{t^{*}}\left(d y_{s}^{*}(\xi) / d \xi\right)^{2} d \xi \\ y^{*}=y /[\lambda], \quad z^{*}=z /[\lambda], \quad t^{*}-t /[t],\end{array}\right\}$

where $\quad I_{v}=\int_{T_{0}}^{T_{v}} k d T, \quad[\lambda]=\rho_{0} \alpha \Delta H_{v} / \dot{q}_{r}^{\prime \prime}, \quad[t]=[\lambda]^{2} / \alpha, \quad$ and

$\dot{\mathrm{q}}_{\mathrm{r}}^{\prime \prime}$ is a reference flux. In terms of these reduced variables, the mathematical problem becomes:

$\frac{\partial \theta}{\partial \tau}+\left(\frac{\frac{\mathrm{d}^{2} \mathrm{y}_{s}^{*}}{\mathrm{dt}^{* 2}}}{\left[\frac{\mathrm{dy_{s } ^ { * }}}{\mathrm{d} t^{*}}\right)^{3}} \zeta \frac{\partial \theta}{\partial \zeta}-\frac{\partial \theta}{\partial \zeta}\right)-\frac{\partial^{2} \theta}{\partial \zeta^{2}}=0$ 


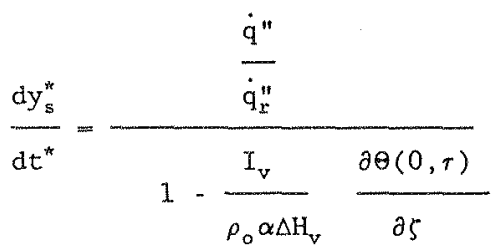

This transformation splits the gasification-induced convection into two terms, the second and third terms in Eq. (12). In order to proceed further analytically, this equation is simplified by neglecting the second term. In support of this approximation, it is noted that this term is exactly zero for all $\tau$ at the surface. Moreover, as $r$ gets large and a steady state is approached, the dominant balance is between the last two terms in the equation. As $r \rightarrow 0$, the first and last terms dominate, as they do at the front of the thermal wave as it advances into the solid. Thus, although some error will inevitably be incurred by neglecting this term, it never makes a dominant contribution to the energy balance.

With this approximation the governing equations become

$\frac{\partial \Theta}{\partial \tau}-\frac{\partial \Theta}{\partial \zeta}-\frac{\partial^{2} \theta}{\partial \zeta^{2}}=0$

$\theta(0, r)=1, \quad \theta(\infty, \tau)=0, \quad \theta(\zeta, 0)=\theta_{0}(\zeta)$

We solve this system of equations for $\partial \theta(0, r) / \partial \zeta$ using the methods of Laplace transform, superposition, and Green's functions and obtain

$\frac{\partial \Theta(0, \tau)}{\partial \zeta}=\frac{\partial \theta_{1}(0, \tau)}{\partial \zeta}+\frac{\partial \theta_{2}(0, r)}{\partial \zeta}$

where

$\frac{\partial \theta_{1}(0, r)}{\partial \zeta}=-1+\frac{1}{2} \operatorname{erfc}\left(\frac{\tau^{\frac{1}{2}}}{2}\right)-\frac{1}{(\pi \tau)^{\frac{\pi}{2}}} \exp (-r / 4)$

$\frac{\partial \Theta_{2}(0, r)}{\partial \zeta}=\frac{\exp (-r / 4) \rho_{0} \alpha \Delta \mathrm{H}_{v}}{2 \pi \mathrm{I}_{\mathrm{v}} \tau^{3 / 2}} \int_{0}^{\mathrm{t}_{\mathrm{v}}^{*}} \frac{\dot{\mathrm{q}}^{\prime \prime}\left[\mathrm{t}_{0}^{*}, \mathrm{~T}\left(0, \mathrm{t}_{0}^{*}\right)\right] \mathrm{G}(\mathrm{A}) d \mathrm{t}_{0}^{*}}{\dot{\mathrm{q}}_{I}^{*}}$

$G(A)=\frac{1}{2 A}+\frac{\exp (1 / 16 A)}{8}(\pi)\left(A^{3}\right)^{\frac{3}{3}}\left[2-\operatorname{erfc}\left(1 / 4 A^{2}\right)\right]$

1 1

$A\left(r, t_{0}^{*}\right)=\frac{}{4 r}+\beta\left(t_{0}^{*}\right), \quad$ and $\quad \beta=\frac{\left(\frac{d y_{s}^{*}(0)}{d t^{*}}\right)^{2}\left(t_{v}^{*}-t_{0}^{*}\right)}{4\left(\frac{1}{4}\right)}$ 
We still require a value for $\mathrm{dy}_{\mathrm{s}}^{*}(0) / \mathrm{dt}^{*}$, the regression rate at the time gasification begins. Consider the preheat period at a $t i m e, t_{v}^{-}=t_{v}-\epsilon$, just before gasification begins. Here $\epsilon$ represents an arbitraxily small interval. Also, consider the gasification period at a time, $t_{v}^{+}=t_{v}+\epsilon$, just after gasification begins. We require that the temperature be continuous at $t=t_{v}$; that is,

$$
\theta\left(y, t_{v}^{-}\right)=\theta\left(y, t_{v}^{+}\right)
$$

It follows that the first and second spatial derivatives of $\theta$ are also continuous. The time derivative, however, is discontinuous because the surface temperature is instantaneously fixed at $\mathrm{T}_{\mathrm{v}}$ when gasification begins. Using these conditions together with the heat conduction equation immediately before and after gasification yields

$\frac{d y_{s}^{*}(0)}{d t^{*}}=\frac{I_{v} \rho_{0} \Delta H_{v}}{\dot{q}_{x}^{\prime \prime} \dot{q}^{\prime \prime}\left(t_{v}\right)} \frac{\partial \theta\left(0, t_{v}^{-}\right)}{\partial t}=\frac{\rho_{0} k\left(T_{v}\right) \Delta H_{v}}{\dot{q}_{r}^{\prime \prime} \dot{q}^{\prime \prime}\left(t_{v}\right)} \frac{\partial T\left(0, t_{v}^{-}\right)}{\partial t}$

where the time derivative of $T\left(0, t_{\mathrm{v}}^{-}\right)$is obtained from the preheating solution.

\section{Summary of the Analytical Solutions}

It will be convenient to nondimensionalize the preheating solution [Eq.(5)] into the following form which is consistent with that of the gasification solution;

$\left[C_{2} T\left(0, t^{*}\right)^{2}+C_{1} T\left(0, t^{*}\right)+C_{0}\right] / I_{v}=\frac{\rho_{0} \alpha \Delta H_{v}}{I_{v} \pi^{*}} \int_{0}^{t^{*}} \frac{\dot{q} "\left[t_{0}^{*}, T\left(0, t_{0}^{*}\right)\right] d t_{0}^{*}}{\left(t^{*}-t_{0}^{*}\right)^{*}}$

where

$\dot{\mathrm{q}}^{\prime \prime}\left[\mathrm{t}^{*} ; \mathrm{T}\left(0, \mathrm{t}^{*}\right)\right]=(1-\mathrm{r}) \dot{\mathrm{q}}_{\mathrm{I}}{ }^{\prime}\left(\mathrm{t}^{*}\right)-\operatorname{\epsilon \sigma } \mathrm{T}\left(0, \mathrm{t}^{*}\right)^{4}-\mathrm{h}_{\mathrm{c}}\left[\mathrm{T}\left(0, \mathrm{t}^{*}\right)\right]\left[\mathrm{T}\left(0, \mathrm{t}^{*}\right)-\mathrm{T}_{0}\right]$

These equations are solved for $T\left(0, t^{*}\right)$ and $\dot{q}^{\prime \prime}\left[t^{*} ; T\left(t^{*}\right)\right]$ for $0 \leq t^{*} \leq t_{v}^{*}$. Also, $\partial \mathrm{T}\left(0, \mathrm{t}_{\mathrm{v}}^{-}\right) / \partial \mathrm{t}$ is calculated from the temperature-versus-time results.

Having these preheating results, the transient mass flux is then obtained from the expression

$$
\dot{\mathrm{m}}^{\prime \prime}\left(\mathrm{t}^{*}\right)=\frac{\dot{\mathrm{q}}^{\prime \prime}\left(\mathrm{t}^{*}\right)}{\Delta \mathrm{H}_{\mathrm{v}}-\frac{\mathrm{I}_{\mathrm{v}}}{\rho_{\mathrm{o}} \alpha} \frac{\partial \theta(0, \tau)}{\partial \zeta}}
$$

where $t^{*}$ in Eq.(23) is the nondimensional time since the onset of gasification.

\section{NUMERICAL PROCEDURE}

The solution to the nonlinear, singular, integral preheating equation, Eq. (21), is obtained by the method of Noble [9]. The numerical evaluation. 
of the integral is equivalent to the linear-with-r approximation used by Panagiotau and Delichatsios [10] in their solution for the preheating of materials with constant properties. Noble's method is also used to evaluate the integral in Eq.(18) of the gasification solution. As was the case for the preheating problem, the gasification problem must be solved repeatedly in order to determine $t^{*}$ from $r$ since the transformation given in Eqs.(11) shows $t^{\star}$ is a function of the history of $d y_{s}^{*} / d t^{*}$. We use the trapezoidal rule to evaluate the integral in Eq. (11).

\section{RESULTS AND DISCUSSION}

Calculations were carried out for PMMA using input data equal to the following or derived therefrom: $\rho_{0}=1190 \mathrm{~kg} / \mathrm{m}^{3}, \quad \Delta \mathrm{H}_{v}=420 \mathrm{~J} / \mathrm{g}$, $k(298 \mathrm{k})=0.193 \times 10^{-3} \mathrm{~kW} / \mathrm{m}-\mathrm{K}, \quad \mathrm{r}=0.05, \quad$ and $\mathrm{c}_{\mathrm{p}}(\mathrm{T})=2.374 \times 10^{-3} \mathrm{~T}+1.13 \mathrm{~J} / \mathrm{g}-\mathrm{K}$ for $378 \mathrm{~K}<\mathrm{T}<550 \mathrm{~K}$ [11]. The value for $\Delta \mathrm{H}_{\mathrm{y}}$ was measured in a nitrogen atmosphere using a differential scanning calorimeter (DSC). Motivated to find a linear relationship that approximates $k(T)$ to a degree that is consistent with other approximations in the model, the above specific heat equation was assumed to be valid down to $298 \mathrm{~K}$. By this equation, $c_{p}(298 \mathrm{~K})=1.84 \mathrm{~J} / \mathrm{g}-\mathrm{K}$ (whereas experimental values are in the range 1.3 to $1.5 \mathrm{~J} / \mathrm{g}-\mathrm{K}$ [12]). Using this approximate value for $\mathrm{c}_{\mathrm{p}}(298 \mathrm{~K})$ and the above values for $\rho_{\circ}$ and $\mathrm{k}(298 \mathrm{~K})$, the thermal diffusivity becomes $\alpha(298 \mathrm{~K})=8.81 \times 10^{-8} \mathrm{~m}^{2} / \mathrm{s}$. Therefore, $\alpha$ remains constant with temperature provided that $\mathrm{k}(\mathrm{T})=2.49 \times 10^{-7} \mathrm{~T}+1.18 \times 10^{-4} \mathrm{~kW} / \mathrm{m}-\mathrm{K}$. Although this function for $\mathrm{k}(\mathrm{T})$ is only approximate below $398 \mathrm{~K}$ (the glass transition temperature), it is more accurate above this temperature where its impact on the model's results is greatest.

Figure 2 shows the results of preheating calculations aimed at simulating the experiments conducted by Kashiwagi and Ohlemiller [13] on vertical samples of PMMA degrading in nitrogen. Calculated results are presented for three different functions for the thermal conductivity, $k$. Use of a constant $k$ evaluated at ambient temperature produces a significant error, whereas a constant $k$ evaluated at the mean of the vaporization and ambient temperatures produces results that are in fairly good agreement with those obtained when $\mathrm{k}(\mathrm{T})$ is allowed to vary linearly and continuously with temperature.
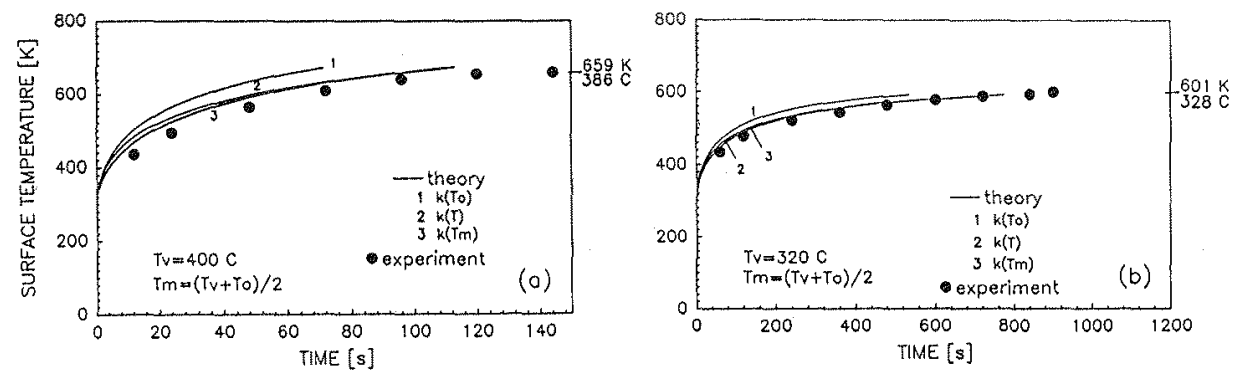

Figure 2. Surface temperature of PMMA exposed to (a) $40 \mathrm{~kW} / \mathrm{m}^{2}$ and (b) $17 \mathrm{~kW} / \mathrm{m}^{2}$ incident heat flux. 

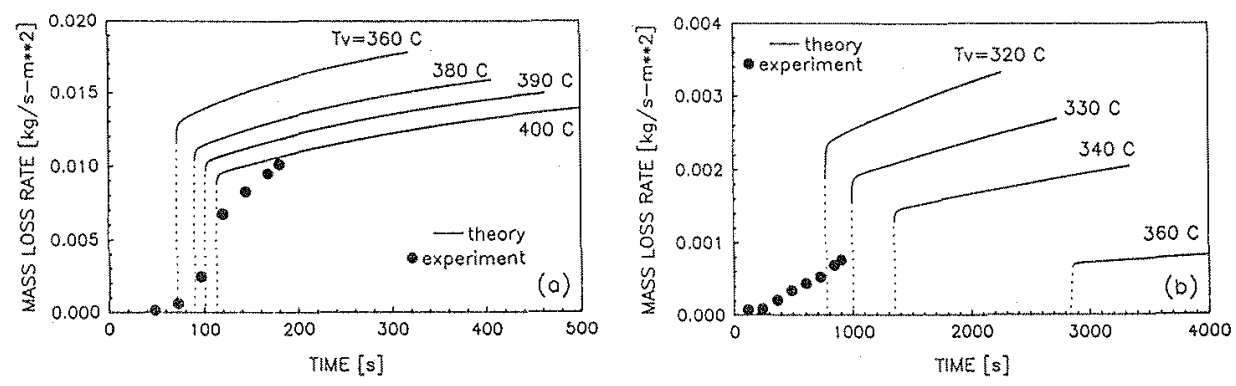

Figure 3. Mass loss rate of PMMA exposed to (a) $40 \mathrm{~kW} / \mathrm{m}^{2}$ and (b) $17 \mathrm{~kW} / \mathrm{m}^{2}$ incident heat flux.

That the predicted surface temperature in Fig. $2 a$ at an exposure of $40 \mathrm{~kW} / \mathrm{m}^{2}$ is higher than the experimental data is consistent with the fact that the theory assumes that the radiant energy is absorbed only at the surface, whereas some of the energy is actually transmitted and absorbed within the sample. The differences between theory and experiment shown in $\mathrm{Fig}$. $2 \mathrm{~b}$ for a $17 \mathrm{~kW} / \mathrm{m}^{2}$ exposure are less than those shown in $\mathrm{Fig}$. $2 \mathrm{a}$ because the longer time scale associated with the lowex flux allows conduction to smooth the effects of indepth absorption. Note that the experimental temperature data suggest that $T_{y}$ is about $390{ }^{\circ} \mathrm{C}$ for the $40 \mathrm{~kW} / \mathrm{m}^{2}$ exposure and about $330^{\circ} \mathrm{C}$ for the $17 \mathrm{~kW} / \mathrm{m}^{2}$ exposure.

Figure 3 a shows the mass loss (gasification) results for the $40 \mathrm{~kW} / \mathrm{m}^{2}$ exposure. As $\mathrm{T}_{\mathrm{v}}$ increases, heat losses from the surface increase, and the calculated mass loss rate decreases. Since $\mathrm{T}_{\mathrm{v}}$ was shown to be about $390^{\circ} \mathrm{C}$, the experimental and theoretical results shown in Fig. $3 a$ are in fairly good agreement, particularly in the later stage of gasification. This suggests that the assumptions of only surface absorption and a single $T_{y}$ are reasonable in this case since experiments [13] have shown that at high flux levels the surface temperature rises rapidly and the reaction zone tends to be relatively thin and near the surface. The temperatures in this zone are high and the melt viscosity is $10 \mathrm{w}$, with the result that indepth degradation products escape easily from the surface. The rapid temperature rise also restricts the time period in which degradation products can actually come off at temperatures below $T_{v}$. Nevertheless, the experimental results show that in-depth absorption and degradation kinetics cause the preheating-to-gasification transition to occur more smoothly than the sudden change assumed in the model.

The mass loss rate results for the $17 \mathrm{~kW} / \mathrm{m}^{2}$ exposure are shown in Fig. 3b. Although the experimental data are limited to relatively short times (due to dripping of the sample), their trend suggests that the

agreement between theory (assuming $\mathrm{T}_{\mathrm{v}}=330^{\circ} \mathrm{C}$ ) and experiment is not as good as was shown for the $40 \mathrm{~kW} / \mathrm{m}^{2}$ exposure. In contrast to the situation under the higher external radiant flux, the reaction zone during the experiment is thicker at the lower external radiant flux, the sample temperature is lower, and the melt viscosity is higher [13]. Consequently, the transport of degradation products to the surface is impeded and there is a greater discrepancy between experiment and theory since the latter assumes 


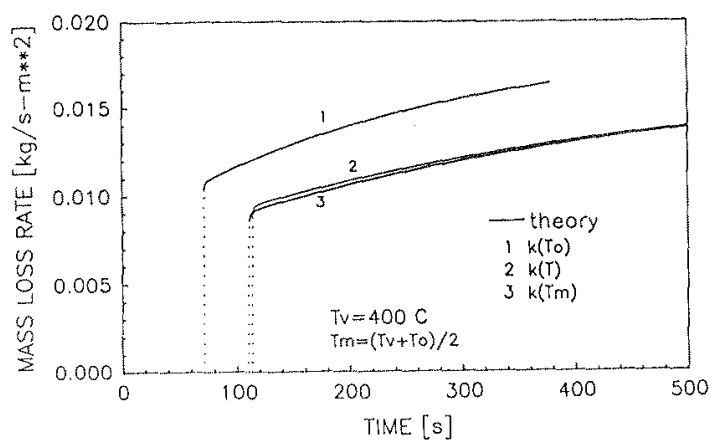

Figure 4. Effect of thermal conductivity, $k$, on calculated mass loss rate of PMMA exposed to $40 \mathrm{~kW} / \mathrm{m}^{2}$.

instantaneous removal of degradation products from the surface. Also, it is clear from the experimental data that the assumptions of gasification at a single $\mathrm{T}_{\mathrm{v}}$ and a single $\Delta \mathrm{H}_{\mathrm{v}}$ are less appropriate at the lower heating rate.

Figure 4 shows that the effect of $k$ on the calculated mass loss rate at an exposure of $40 \mathrm{~kW} / \mathrm{m}^{2}$ is consistent with that shown for the preheat surface temperature results; that is, a constant $k$ evaluated at the mean of $\mathrm{T}_{0}$ and $\mathrm{T}_{\mathrm{v}}$ produces results that are in reasonably good agreement with those produced when $k(T)$ varies linearly and continuously with temperature. Although not shown here, a similar effect on calculated mass loss rate was found at an exposure of $17 \mathrm{~kW} / \mathrm{m}^{2}$.

\section{SURMARY AND CONCLUSTONS}

An analytical model has been developed for the transient gasification of a noncharring, thermally-thick material subjected to a time-dependent heat flux. The model assumes that both $\mathrm{T}_{\mathrm{v}}$ and $\Delta \mathrm{H}_{\mathrm{v}}$ are constant and that radiant flux is absorbed only at the surface of the material. Timedependent radiative and convective heat losses from the surface are included. Temperature-dependent thermal properties are permitted provided that the thermal diffusivity is constant. Calculated results were compared to experiments with PMMA. Agreement between theory and experiment was much better for a high $\left(40 \mathrm{~kW} / \mathrm{m}^{2}\right)$ exposure than for a $10 \mathrm{w}\left(17 \mathrm{~kW} / \mathrm{m}^{2}\right)$ exposure. The model's assumptions of constant $T_{v}$, no in-depth absorption, and no indepth gasification are not appropriate for the lower heating rate where sub-surface processes play a significant role. Further improvements in predictive capability will require explicit representation of these processes. Variable thermal properties, however, were shown to be noncrucial provided an appropriate effective temperature was chosen for their evaluation.

\section{REFERENCES}

1. Peacock, R.D. and Bukowski, R.W., "A Prototype Methodology for Fixe Hazard Analysis", Fire Technology, 26: 1, 15-40, 1990. 
2. Tewarson, A. and Pion, R.F., "Flammability of Plastics. I. Burning Intensity", Comb. and Flame, 26, 85-103, 1976.

3. Vovelie, C., Akrich, R. and Delfau, J-L., "Thermal Degradation of Solid Materials Under a Variable Heat Flux", Twentieth Sym. (Int.) on Combustion, pp. 1647-1654, The Combustion Institute, Pittsburgh, 1984.

4. Vovelle, C., Akrich, R., Delfau, J-L. and Gresilland, S., "Influence of the Thickness on the Thermal Degradation of PMMA", Fire Safety Science - Proceedings of the First International symposium, pp. 473-482, Hemisphere, Washington, D.C., 1986.

5. Vovelle, C., Delfau, J-L., Reuillon, M., Bransier, J. and Laraqui, N., "Experimental and Numerical Study of the Thermal Degradation of PMMA", Int. Meeting of Fire Research and Test Centres, Proceedings, Avila. Spain. October 7-9, 1986, pp. 43-66, Instituto Tecnologico de Seguridad, MAPFRE (ITSEMAP), Madrid, 1986.

6. Saito, K., Delichatsios, M.A., Venkatesh, S., and Alpert, R.L., "Measurements and Evaluation of Parameters Affecting the Preheating and Pyrolysis of Noncharring Materials", Fall Tech. Meeting, ESCI, Combustion Institute, Clearwater Beach, FL, December 5-7, 1988.

7. Delichatsios, M.A. and deRis, J., "Asymptotic Analysis of Surface Temperature Histories Including Nonlinear Radiation Losses", Fa11 Tech. Meeting, ESCI, Combustion Institute, Clearwater Beach, FL, December $5-7,1988$.

8. Carslaw, H.S., and Jaeger, J.C., Conduction of Heat in Solids, 2nd ed., pp. 11 and 76, Oxford Univ. Press, Oxford, 1959.

9. Noble, B., "The Numerical Solution of Nonlinear Integral Equations and Related Topics", Nonlinear Integral Equations, ed. P.M. Anselone, pp. 236-238, University of Wisconsin Press, Madison, WI, 1964.

10. Panagiotau, T. and Delichatsios, M.A., "A Numerical Solution for the Surface Temperature Rise History of a Material Including Surface Reradiation Losses", FMRC Tech. Report J.I.OQ0J1.BU, Factory Mutual Res. Corp., Norwood, MA, December 1989.

11. Gaur, U., Suk-fai, L., Wunderlich, B.B. and Wunderlich, B., "Heat Capacity and Other Thermodynamic Properties of Linear Macromolecules, VI. Acrylic Polymers", J. Phys. Chem. Ref. Data, 11: 4, 1065-1088, 1982.

12. Wunderlich, W., "Physical Constants of Poly(Methyl Methacrylate)", Polymer Handbook, 2nd ed., ed. Brandrup, J. and Immergut, E.H., p. V-56, John Wiley, 1975.

13. Kashiwagi, T. and Ohlemiller, T.J., "A Study of Oxygen Effects on Nonflaming Transient Gasification of PMMA and PE during Thermal Irradiation", Nineteenth Sym. (Int.) on Combustion, pp. 1647-1654, The Combustion Institute, Pittsburgh, PA, 1982. 